\title{
Vesselplasty for the treatment of osteoporotic vertebral compression fractures with peripheral wall damage: A retrospective study
}

Chongqing Xu ( $D$ 809663990@qq.com )

Long Hua Hospital https://orcid.org/0000-0001-9654-793X

Mengchen Yin

Long Hua Hospital

\section{Wen Mo}

Long Hua Hospital

\section{Research article}

Keywords: vesselplasty, osteoporotic vertebral compression fractures, treatment, retrospective study

Posted Date: November 18th, 2020

DOI: https://doi.org/10.21203/rs.3.rs-107453/v1

License: (c) (1) This work is licensed under a Creative Commons Attribution 4.0 International License.

Read Full License 


\section{Abstract \\ Background}

The clinical efficacy of vertebroplasty and kyphoplasty treating osteoporotic vertebral compression fractures (OVCF) has been widely recognized in recent years. However, there are also disadvantages of bone cement leakage (BCL), limited correction of kyphosis and recovery of vertebral height. Nowadays, in view of these shortcomings, vesselplasty has been widely used in clinical practice. The objective of this study is to assess its clinical effect and application value for the treatment of OVCF with peripheral wall damage.

\section{Methods/Design:}

All 62 patients (70 vertebrae) treated for OVCF with peripheral wall damage using vesselplasty were involved and retrospectively analyzed. The data collection included operation time, volume of bone cement, relevant surgical complications, visual analog scale (VAS), Oswestry disability index (ODI), vertebral body height and kyphosis Cobb angle.

\section{Results}

The time of operation was $20-65(34.5 \pm 10.5)$ minutes. The volume of bone cement was $3-8(5.3 \pm 1.3)$ $\mathrm{ml}$. VAS and ODI at different time points after operation were decreased compared with before operation (all $\mathrm{P}<0.05$ ). There were no statistical differences between VAS or ODI at different postoperative time points $(P>0.05)$. Vertebral body height and Cobb angle at different time points after operation were improved compared with before operation (all $P<0.05)$. There were no statistical differences between vertebral body height or Cobb angle at different postoperative time points (all $P>0.05$ ).

\section{Conclusion}

Vesselplasty can reduce the risk of BCL and better control the dispersion of bone cement in the treatment of OVCF. It has a definite effect in relieving pain, restoring the vertebral body height and correcting the kyphosis caused by injured vertebrae, especially in OVCF with peripheral wall damage. Therefore, vesselplasty is safe and worthy of clinical application.

\section{Background}

With the aging of population, the incidence of osteoporotic vertebral compression fractures (OVCF) is significantly increasing, and it has been a common disease in spine surgery. OVCF can cause severe back pain, some patients may be accompanied with varying degrees of neurological impairment, which seriously affects the life quality of patients.[1] Since traditional open surgery is always accompanied with 
surgical trauma, and osteoporosis often leads to loosening of internal fixation,[2] minimally invasive approaches such as percutaneous vertebroplasty[3] (PVP) and percutaneous kyphoplasty[4] (PKP) have become the first choice for the treatment of OVCF.

PVP and PKP can immediately stabilize the fracture, obviously relieve the pain and help patients recover early activity. However, both methods have disadvantages of high incidence of bone cement leakage $(B C L)$, limited correction of kyphosis and recovery of vertebral height. BCL can cause nerve and spinal cord injury which leads to motor dysfunction or paraplegia, and may result in serious complications such as re-fracture of adjacent vertebra and pulmonary embolism.[5, 6]

In view of the shortcomings of PVP and PKP, A-Spine Holding Group Corporation (Taipei, Taiwan) developed the Vessel-X bone-filling mesh container, and a new technical approach, vesselplasty (vertebral augmentation using Vessel-X bone filler) emerged.[7] Later, relevant studies indicated that compared with irregular distribution of bone cement in PVP/PKP, vesselplasty can effectively control BCL.[8, 9]

In the past decade, vesselplasty has been widely used in clinical practice, especially for patients with different degrees of peripheral wall damage, but no symptoms of nerve and spinal cord injury. It can improve the safety of surgery and reduce the incidence of BCL. Therefore, we aim to conduct a retrospective study using vesselplasty for the treatment of OVCF with peripheral wall damage, and evaluate its clinical effect and application value.

\section{Materials And Methods}

\subsection{Patient Case Selection and General Information}

Institutional review board approval was obtained from our ethics committee, and the study was conducted based on principles of Declaration of Helsinki. Patients treated for OVCF using vesselplasty in database records of our hospital were retrospectively collected and analyzed between January 1, 2017, to December 31, 2019. For inclusion in this study, all participant subjects were diagnosed as osteoporosis through bone mineral density (BMD) examination, and should have complete imaging studies including radiographs, computed tomography (CT) scans and magnetic resonance (MR) images, which were used

to observe fracture and confirm the vertebral peripheral wall damage. None of the patients had symptoms and signs of nerve and spinal cord injury. Available clinical data was also necessary, including demographic characteristic, chief complaint, neurospinal function and complications.

Based on the criteria, we finally selected a total of 62 consecutive cases (70 vertebrae) from our database of patients, including 19 males and 43 females, with an average age of 70.2 \pm 9.6 years (54-82 years). There were 62 vertebrae with anterior wall damage, 49 vertebrae with lateral wall damage, 45 vertebrae with upper endplate damage, 10 vertebral bodies with lower endplate damage, and 13 vertebral bodies with posterior wall damage. The range of affected vertebral segment covered from thoracic (34) to lumbar (36) (Table 1). 


\subsection{Surgical procedure and Postoperative Management}

Intravenous anesthetize the patient in prone position. Make a small skin incision, puncture into vertebral body with bone access needle through unilateral pedicle of the vertebral arch and set up the working channel under X-ray monitoring. Then implant the Vessel-X bone-filling mesh container to the predetermined position through the channel, and progressively fill the container with bone cement until it oozes out of the mesh and enters into the space of cancellous bone. Stop the operation if the cement distributes well and the fracture reduction is satisfactory. Finally, remove the working channel, withdraw the instruments and suture the incision (Figure 1).

After operation, patients were treated with analgesia, anticoagulation and infection prevention. After 24 hours, they could get off the bed under the protection of lumbar support and exercise their lumbodorsal muscles. Postoperative radiograph and CT scans were reexamined to observe the reduction of vertebrae and diffusion of bone cement. Anti osteoporosis treatment was standardized and BMD was rechecked regularly.

\subsection{Data Collection}

Operation time and volume of bone cement injected into each vertebra were recorded. Relevant surgical complications such as $\mathrm{BCL}$, infection, ectopic embolism, and systemic manifestations were also collected. Clinical symptoms including pain and dysfunction were assessed based on visual analog scale (VAS) (0-10 points, 0 points for no pain, and 10 points for the most severe pain). The Oswestry disability index (ODI) (higher score indicates severer dysfunction) was used to assess the improvement in the motor function status of patients. VAS scores and ODI were recorded routinely on admission, at 24 hours, 1 month and 3 months post-operation and at the last follow-up.

\subsection{Radiographic assessment}

Location of BCL was recorded according to Intraoperative and postoperative radiograph and CT scan. Vertebral body height of affected segment was assessed based on recommendation of Pflugmacher et al.,[10] which was defined as the distance between upper and lower endplates on lateral radiograph. The kyphosis Cobb angle was measured based on method proposed by Kuklo et al.,[11] that is, the angle between the extension line of the upper endplate of the upper vertebra and the extension line of the lower endplate of the lower vertebra, with the affected vertebra as the center. Radiographic assessments were also recorded routinely on admission, at 24 hours, 1 month and 3 months post-operation and at the last follow-up.

\subsection{Statistical analysis}

All statistical analyses were performed using Statistical Packages of Social Sciences (SPSS) software (version 22.0). A $p$ value of $<0.05$ was considered statistical significance. Means and standard deviations ( $x \pm s$ ) were used to describe quantitative data including vertebral body height, Cobb angle, VAS and ODI. Normal distribution of the data were assessed by the Kolmogorov-Smirnov test and all 
these variables showed a normal distribution. Differences in these variables before and after the operation were analyzed with a two-tailed paired Student's $t$-test.

\section{Result}

\subsection{0peration Time and Volume of Bone Cement}

Of the total 62 consecutive cases (70 vertebrae), vesselplasty went well, all patients tolerated the operation, and their vital signs were stable. The time of operation was $20-65(34.5 \pm 10.5)$ minutes, and the volume of bone cement injected into each vertebral body was $3-8(5.3 \pm 1.3) \mathrm{ml}$, as shown in Table 1 .

\subsection{VAS and ODI}

All the patients were followed up for 4-6 months, with an average of $5.1 \pm 0.4$ months. VAS scores and ODI at different time points after operation were decreased compared with before operation (all $\mathrm{P}<0.05)$, which indicated significant alleviation of pain and improvement of motor function. There were no statistical differences between VAS scores or ODI at different postoperative time points (all $P>0.05$ ) (Table 2).

\subsection{Vertebral Body Height and Cobb Angle}

Similar to VAS and ODI, anterior border height of vertebral body and Cobb angle at different time points after operation were improved compared with before operation (all $\mathrm{P}<0.05$ ), which indicated significant fracture reduction and deformity correction. There were no statistical differences between vertebral body height or Cobb angle at different postoperative time points (all $\mathrm{P}>0.05$ ) (Table 3).

\subsection{Complications}

There was no nerve or spinal cord injury after operation. No infection, ectopic embolism, and systemic manifestations occurred. There were 6 cases of postoperative BCL, among which 3 cases leaked to paravertebral area, 2 cases leaked to upper or lower endplate, 1 case leaked into spinal canal and 1 case leaked through puncture channel, but without relevant symptoms. The incidence of BCL was 10\% (Table 4).

\section{Discussion}

$\mathrm{BCL}$ is the most common problem in PVP/PKP for the treatment of OVCF, especially in OVCF cases with peripheral wall damage. At present, Yeom's[12] classification of BCL is widely recognized and applied in clinical practice. It divides BCL into 3 types: type B (leakage via the basivertebral vein), type S (leakage via the segmental vein) and type $C$ (leakage through a cortical defect). Among which type $C$ is the most common, and can occur in any part around the vertebral body, such as intervertebral disc, paravertebral body, posterior vertebral edge, etc. Studies show that in PVP, the direct infusion of bone cement into vertebrae can generate high infusion pressure, which make the cement easy to leak, thus the incidence of 
BCL is as high as $19 \% \sim 76 \%$, with an average of $29 \%[13,14,15]$. Later, PKP is developed, in which balloon is used to form a cavity in the vertebral body and restore the height, then bone cement is injected under low pressure, and that reduce the incidence of BCL to about 8\%.[16] However, for those OVCF with peripheral vertebral wall damage, the fracture can be further enlarged due to the expansion of the injured vertebral body, which increases the risk of BCL. There is a high risk of spinal cord (cauda equina) or nerve injury especially in the case with posterior wall damage.[17]

The basic principle of vesselplasty is to insert a distal detachable mesh container (Vessel- $\mathrm{X}$ ) into the injured vertebra through a working path, inject bone cement and pressurize the container to gradually expand, in order to restore the height of the compressed vertebral body and correct kyphosis. When bone cement starts to solidify, remove the container, and keep bone cement in the vertebral body. In the whole procedure, bone cement is always wrapped in the container, instead of pouring bone cement directly into the vertebral body, so that the container can prevent BCL in the vertebral body with damaged anterior or posterior wall. Briefly, vesselplasty is performed based on mechanics and hydrodynamics. The mesh container has a dense polymer net layered structure with different capacity designed, which can significantly reduce cement leakage. Studies indicated that PVP, PKP and vesselplasty all achieved satisfactory results in pain relief, but PKP did better in restoring vertebral body height, while vesselplasty had lower incidence of BCL.[18, 19] The Vessel-X container is made up of $100 \mu \mathrm{m}$ mesh, and the bone cement oozing from within the container can get a good grip with cancellous bone, which is very suitable for the vertebral fracture with peripheral wall damage.[18] In our study, none of the cases had BCL into spinal canal, 2 cases had paravertebral leakage which defined as type B,[12] and only 1 case leaked through puncture channel into posterior soft tissue as type $C$. Those patients with BCL did not have clinical symptoms, and no special treatment was given.

In PKP, bone cement won't be injected until vertebral expansion is completed and balloon is removed. Therefore, it is easy to cause the vertebra collapsing again due to the poor mechanical properties of the cavity. In vesselplasty, bone cement is directly injected to pressurize, and the cement dispersing outside the container can help to expand the vertebral body. Thus in theory, vesselplasty can better restore vertebral body height and correct kyphosis. However, further clinical trials are needed to compare the difference between vesselplasty and PKP. Chen et al.[20] found that vesselplasty and PKP had statistical significance compared with PVP in restoring vertebral body height, while there was no difference between the former two. As for the degree of recovering of vertebral body height, the study results are different, but all have shown significant improvement compared with before operation. In addition, the compressed vertebral body can not only cause kyphosis, but also reduce the ability in load dispersing of upper and lower intervertebral disc, resulting in fracture of adjacent vertebra or re-fracture of injured vertebra. In the treatment of OVCF, it is necessary strengthening the injured vertebral body, as well as restoring its height. [21]

According to our results, the postoperative ODI and VAS scores of patients decreased obviously, indicating that their functional status and pain caused by fracture were significantly improved. Our radiographic assessment showed that vertebral body height increased and Cobb angle was corrected 
significantly, suggesting satisfactory improvement of spinal deformity and restoration of vertebral body height through cement injection using mesh container. Besides, there were only 3 cases of $B C L$, and none of them caused relevant symptoms, which indicated sound safety of vesselplasty.

The current study has several limitations. First of all is its relatively low number of patients. For that vesselplasty has not been widely popularized, there were totally 62 patients involved in the study. Larger sample population will allow for more meaningful statistical testing and smaller deviation. Another limitation is the short follow-up period. The longest period in this study was 6 months since we initially believed that longer period of follow-up would reduce patients' compliance and make data collection more difficult. However, longer period up to 1 or 2 years may Improve the reliability of evidence. Therefore, large sample, multicenter and long follow-up studies should be performed in our future clinical work to provide spine surgeons with the best evidence-based information.

\section{Conclusion}

Vesselplasty can reduce the risk of $\mathrm{BCL}$ and better control the dispersion of bone cement in the treatment of OVCF. It has a definite effect in relieving pain, restoring the vertebral body height and correcting the kyphosis caused by injured vertebrae, especially in OVCF with with peripheral wall damage. Therefore, vesselplasty is safe and worthy of clinical application.

\section{Abbreviations}

OVCF (osteoporotic vertebral compression fractures)

PVP (percutaneous vertebroplasty)

PKP (percutaneous kyphoplasty)

$\mathrm{BCL}$ (bone cement leakage)

BMD (bone mineral density)

CT (computed tomography)

MR (magnetic resonance)

VAS (visual analog scale)

ODI(Oswestry disability index)

SPSS (Statistical Packages of Social Sciences)

\section{Declarations}




\section{Ethics approval and consent to participate}

The case was reviewed by the Longhua Hospital Ethics Committee and ethical approval was waived as written consent was obtained from the patient.

\section{Consent for publication}

Written patient consent was obtained for publication of all aspects of the case including personal and clinical details and images, which may compromise anonymity.

\section{Availability of data and material}

All supporting data can be provided upon request to the authors.

\section{Competing interests}

All authors read and approved the final manuscript and declare that they have no competing interests.

\section{Funding}

No funding was obtained for this study.

\section{Authors' contributions}

XCQ and YMC are co-first authors of this manuscript. XCQ designed the study and collected the data. YMC did the data analysis. XCQ wrote the manuscript. MW revised the manuscript and decided to submit the manuscript for publication. All authors read and approved the final manuscript.

\section{Acknowledgements}

I want to thank my love, Du Ying, no matter how difficult it is, she never gives up, always cares for me, silently supports me, and gives me courage when I lose confidence. Without her help, understanding, tolerance and support, I believe that the life of a $\mathrm{PhD}$ in these three years will be very different.

\section{References}

1. Kovacs FM, Abraira V, Zamora J, et al. Correlation between pain, disability, and quality of life in patients with common low back pain. Spine (Phila Pa 1976). 2004;29:206-210.

2. Arabmotlagh M, Nikoleiski SC, Schmidt S. Radiological evaluation of kyphoplasty with an intravertebral expander after osteoporotic vertebral fracture. J Orthop Res. 2019;37:457-465.

3. Galibert P, Deramond H, Rosat P, et al. Preliminary note on the treatment of vertebral angioma by percutaneous acrylic vertebroplasty. Neurochirurgie , 1987;33:166-168.

4. Garfin SR, Yuan HA, Reiley MA. New technologies in spine: kyphoplasty and vertebroplasty for the treatment of painful osteoporotic compression fractures. Spine. 2001;26:1511-1515. 
5. Zhao Y, Liu T, Zheng Y, et al. Successful percutaneous retrieval of a large pulmonary cement embolus caused by cement leakage during percutaneous vertebroplasty: case report and literature review. Spine (Phila Pa 1976). 2014;39:E1616-1621.

6. Kita K, Takata Y, Higashino K, et al. Surgical removal of circumferentially leaked polymethyl methacrylate in the epidural space of the thoracic spine after percutaneous vertebroplasty. Surg $\mathrm{J}$ (NY). 2017;3:e1-e5.

7. Zhang Z, Kuang G, Dong Z, et al. Percutaneous vertebral augmentation with the Vessel-X bone void filling container system: A preliminary clinical trial. Chin JM in Inv Surg. 2007;7:143-145.

8. Zheng Z, Luk KD, Kuang G, et al. Vertebral augmentation with a novel vessel-x bone void filling container system and bioactive bone cement. Spine. 2007;32:2076-2082.

9. Yang XG, Wu G, Sun YY, et al. Vesselplasty using the Mesh-Hold ${ }^{\text {TM }}$ bone-filling container for the treatment of pathological vertebral fractures due to osteolytic metastases: A retrospective study. Eur J Radiol. 2020;126:108962.

10. Pflugmacher R, Kandziora F, Schroeder RJ, et al. Percutaneous balloon kyphoplasty in the treatment of pathological vertebral body fracture and deformity in multiple myeloma: a one-year follow-up. Acta Radiologica. 2006;47:369-376.

11. Kuklo TR, Polly DW, Owens BD, et al. Measurement of thoracic and lumbar fracture kyphosis: evaluation of intraobserver, interobserver, and technique variability. Spine (Phila Pa 1976). 2001;26:61-65.

12. Yeom JS, Kim WJ, Choy WS, et al. Leakage of cement in percutaneous transpedicular vertebroplasty for painful osteoporotic compression fractures. J Bone Joint Surg Br. 2003;85:83-89.

13. Phillips FM, Pfeifer BA, Lieberman IH, et al. Minimally invasive treatments of osteoporotic vertebral compression fractures vertebroplasty and kyphoplasty. Instrcourse Lect. 2003;52:559-567.

14. Zhu SY, Zhong ZM, Wu Q, et al. Risk factors for bone cement leakage in percutaneous vertebroplasty: a retrospective study of four hundred and eighty-five patients. Int Orthop. 2016;40:1205-1210.

15. El SA, Kelm A, Meier S, et al. Intraoperative PEEP-ventilation during PMMA-injection for augmented pedicle screws: improvement of leakage rate in spinal surgery. Eur J Trauma Emerg Surg. 2013;39:461-468.

16. Hadjipavlou AG, Tzermiadianos MN, Katonis PG, et al. Percutaneous vertebroplasty and balloon kyphoplasty for the treatment of osteoporotic vertebral compression fractures and osteolytic tumours. J Bone Joint Surg Br. 2005;87:1595-1604.

17. Lin EP, Ekholm S, Hiwatashi A, et al. Vertebroplasty: cement leakage into the disc increases the risk of new fracture of adjacent vertebral body. AJNR. 2004;25:175-180.

18. Flors L, Lonjedo E, Leiva-Salinas C, et al. Vesselplasty: a new technical approach to treat symptomatic vertebral compression fractures .Ajr Am J Roentgenol. 2009;193:218-226.

19. Fu GY, Geng XP, Wang X, et al. Bone filling mesh container versus balloon percutaneous kyphoplasty repairs osteoporotic vertebral compressive fracture. Chinese Journal of Tissue Engineering Research. 2016;20:7858-7864. 
20. Chen C, Li D, Wang Z, et al. Safety and efficacy studies of vertebroplasty, kyphoplasty, and meshcontainer-plasty for the treatment of vertebral compression fractures: preliminary report. PloS One. 2016;11:e0151492.

21. Liu XW, Wei DX, Peng XT, et al. Limitation of the PKP balloon in the treatment of painful thoracolumbar vertebral body compression fractures and the alternative solution. J Med Imaging. 2013;23:1457-1460.

\section{Tables}

\section{Table 1. General Information of the Patients}




\begin{tabular}{|c|c|c|}
\hline No. & Clinical Information & Number \\
\hline & Sex (Male/Female) & \\
\hline 1 & Mean age (years) & $19 / 43$ \\
\hline 2 & & $70.2 \pm 9.6$ \\
\hline \multirow[t]{12}{*}{3} & Affected vertebral segment & \\
\hline & T7 & 1 \\
\hline & T8 & 3 \\
\hline & T9 & 4 \\
\hline & T10 & 6 \\
\hline & T11 & 9 \\
\hline & T12 & 11 \\
\hline & L1 & 13 \\
\hline & L2 & 11 \\
\hline & L3 & 8 \\
\hline & L4 & 4 \\
\hline & Total (thoracic/lumbar) & $70(34 / 36)$ \\
\hline \multirow[t]{6}{*}{4} & Peripheral wall damage & \\
\hline & anterior wall damage & 62 \\
\hline & lateral wall damage & 49 \\
\hline & posterior wall damage & 13 \\
\hline & upper endplate damage & 45 \\
\hline & lower endplate damage & 10 \\
\hline 5 & Mean operation time (min) & $34.5 \pm 10.5$ \\
\hline 6 & Mean volume of cement to each vertebra (ml) & $5.3 \pm 1.3$ \\
\hline
\end{tabular}

Table 2. Comparison of VAS and ODI before and after Vesselplasty 


\begin{tabular}{|llllll|}
\hline Index & $\begin{array}{l}\text { Preoperative 1 } \\
\text { day }\end{array}$ & $\begin{array}{l}\text { Postoperative 1 } \\
\text { day }\end{array}$ & $\begin{array}{l}\text { Postoperative 1 } \\
\text { month }\end{array}$ & $\begin{array}{l}\text { Postoperative 3 } \\
\text { months }\end{array}$ & $\begin{array}{l}\text { Last } \\
\text { follow-up }\end{array}$ \\
\hline VAS & $7.96 \pm 0.54$ & $2.21 \pm 0.83^{\mathrm{ab}}$ & $1.96 \pm 0.47^{\mathrm{ab}}$ & $2.13 \pm 0.75^{\mathrm{ab}}$ & $\begin{array}{l}2.29 \pm \\
0.50^{\mathrm{ab}}\end{array}$ \\
\hline ODI & $81.33 \pm 9.27$ & $40.92 \pm 7.45^{\mathrm{ab}}$ & $37.26 \pm 8.38^{\mathrm{ab}}$ & $36.52 \pm 9.22^{\mathrm{ab}}$ & $\begin{array}{l}39.17 \pm \\
8.56^{\mathrm{ab}}\end{array}$ \\
\hline
\end{tabular}

Table 3. Comparison of Vertebral Body Height (Anterior Border) and

Cobb Angle before and after Vesselplasty

\begin{tabular}{|lcllll|}
\hline Content & Preoperative & $\begin{array}{l}\text { Postoperative 1 } \\
\text { day }\end{array}$ & $\begin{array}{l}\text { Postoperative 1 } \\
\text { month }\end{array}$ & $\begin{array}{l}\text { Postoperative 3 } \\
\text { months }\end{array}$ & $\begin{array}{l}\text { Last } \\
\text { follow-up }\end{array}$ \\
\hline $\begin{array}{l}\text { VBH } \\
(\mathrm{mm})\end{array}$ & $15.64 \pm 2.18$ & $22.15 \pm 1.93^{\mathrm{ab}}$ & $21.76 \pm 1.32^{\mathrm{ab}}$ & $21.03 \pm 1.78^{\mathrm{ab}}$ & $\begin{array}{l}20.49 \pm \\
1.52^{\mathrm{ab}}\end{array}$ \\
\hline $\mathrm{CA}\left(^{\circ}\right)$ & $23.57 \pm 3.29$ & $12.13 \pm 1.45^{\mathrm{ab}}$ & $12.28 \pm 2.06^{\mathrm{ab}}$ & $12.90 \pm 1.94^{\mathrm{ab}}$ & $\begin{array}{l}13.22 \pm \\
1.81^{\mathrm{ab}}\end{array}$ \\
\hline & & & & \\
\hline
\end{tabular}

Table 4. Complications of Vesselplasty

\begin{tabular}{|ll|}
\hline Complications & Number \\
\hline Nerve or spinal cord injury & \\
Infection & 0 \\
& 0 \\
\hline Ectopic embolism & 0 \\
\hline $\begin{array}{l}\text { Bone cement leakage } \\
\text { paravertebral area }\end{array}$ & 3 \\
\hline upper or lower endplate & 2 \\
\hline \multicolumn{1}{|c|}{ into spinal canal } & 1 \\
\hline \multicolumn{1}{|c|}{ through puncture channel } & 1 \\
\hline
\end{tabular}

\section{Figures}




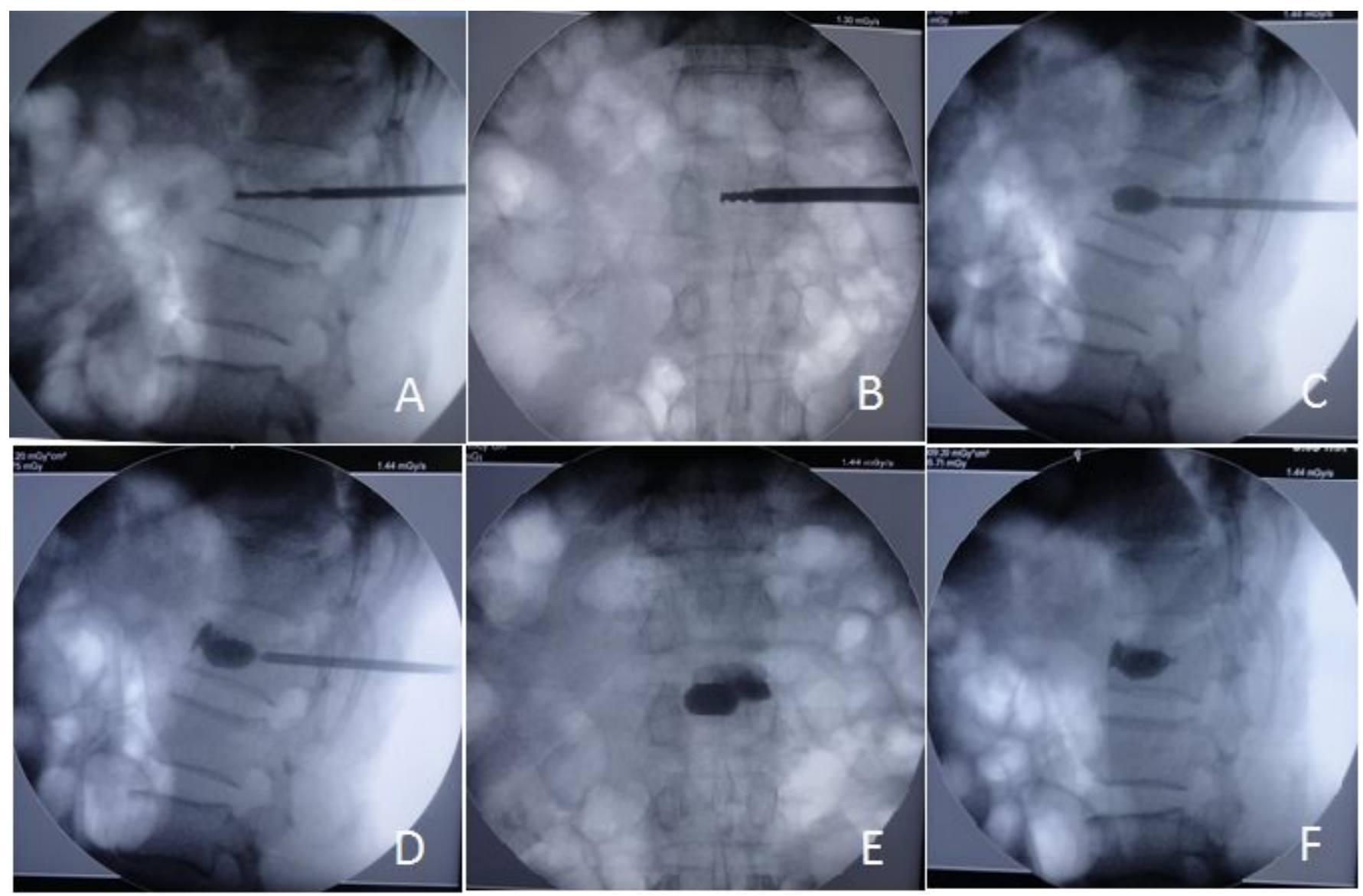

\section{Figure 1}

This is a typical case (A-G) showing the procedure of vesselplasty. The lateral position view shows partial recovery of vertebral body height and Cobb angle. There is no leakage of bone cement. The bone cementmesh container complex is fully filled at the lesions. 